\title{
豚の生理反応に及ぼす環境温度と風速の影響 および風速を含めた体感温度表示の試み
}

\author{
池内俊策・山本あや*・山本禎紀 \\ 石島大学生物生産学部，福山市 720 \\ (1983. 6. 10 受付)
}

\begin{abstract}
要 約 ケージ飼育のランドレース種去勢豚 8 頭を用いて, 呼吸数, 心拍数, 直温腸括よび皮薄温（耳

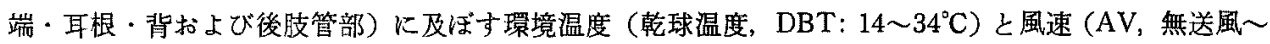
$2 \mathrm{~m} / \mathrm{s}$ ) の影響を観察し，体表温度に及ぽす両者の作用関係を求め，風速を含めた体感温度の表示を試み た. 1) DBT の上昇に伴う皮覻温の变化は, $22^{\circ} \mathrm{C}$ 以下の温域で大きく， $28^{\circ} \mathrm{C}$ 以上の温域で小さかった.

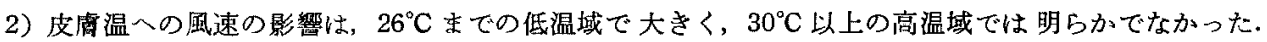
各部位皮苚温変化の差異は， $26^{\circ} \mathrm{C}$ 以上の高温域で消失した，3）呼吸数は DBT の上后に伴い增加し，

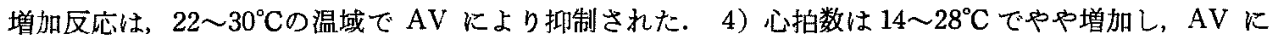

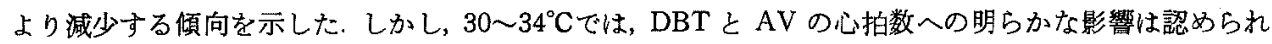

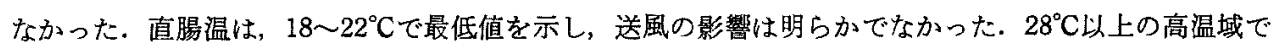
は，送風によって，上昇した直腸温の明らかな降下も，また高温による明らかな上昇反応も認められな かった．5）測定項目のらち DBT と AV の变化に対する反応の顕著であった皮膚温を指標に，DBT と $\sqrt{\mathrm{AV}}$ の作用割合を求め, 両者を一元化した体感温度を，次のように提示し，その意義について考察 した. $\mathrm{ET}(\mathrm{DBT}, \mathrm{AV})=\mathrm{DBT}-4 \cdot \sqrt{\mathrm{AV}}$ ，(ET $(\mathrm{DBT}, \mathrm{AV})$ ：風速を加味した体感温度， $\left.{ }^{\circ} \mathrm{C}\right)$.
\end{abstract}

日畜会報, 55 (11)：815-820,1984

風は，対流と蒸発による家苗の放熱を高める。したが $っ て ，$ 暑熱期の送風や寒冷期の防風は，畜舎の温熱環境 を制御する手段として，厸く利用されてきている1》。

対流による放熱量は，主として体表温々気温の差に支 配され，低温域で大きく，環境温度が体表温に近づく高 温域では著しく減少する。, 一方, 高温域での放熱は, 蒸 散に传存することになるが，体表からの蒸散能は，汗腺 を含む体表構造やその機能と関保するもので，風の効 果に挍いても，各家畜に固有の特改が認められると考え られる.

MOUNT and INGRAM ${ }^{3)}$ は，豚の放熱量 (顕熱) 飞及活 寸環境温度と風の影響について検討しており,この結果 から，風速 $1 \mathrm{~m} / \mathrm{s}$ の作用に相当する環境温度の低下は， 10〜 $18^{\circ} \mathrm{C}$ と大きなるのになると推定され，さらに， CLOSE $5^{42}$ は, 子豚の産熱量に及洔す影響から, 風速 $0.05 \mathrm{~m} / \mathrm{s}$ の增加が環境温度 $1^{\circ} \mathrm{C}$ の低下に相当すること を明らかにしている，また，宇和川らら占，璠の皮膚温

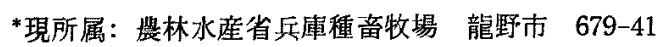

の変化から環境温度と風速の作用割合を求めて，体感温 度の表示を試みている。

家畜の体感温度表示については，すでに温・湿度につ

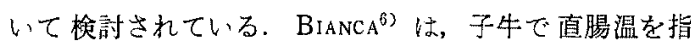
標に，INGRAM は，胅で，体温の上帠染を，また，三村 $ら^{\mathrm{B}-10)}$ は，乳牛，原，熖でそれぞれ呼吸数を生理指標に $し て$, 乾球温度と湿湬温度の作用割合から体感温度の表 示を試みているが，風を含めた具体的な研究は少ない。

温熱環境を構成する要素を生理的に評洒し，一元化す ることは，家畜の体温調節の特徵を理解する上でる，末 た，温熱環境を有効に制御する基礎的研究として子役立 つと考えられる，本報では肉豚に少よぼす風速作用を， 主として皮有温を生理指標に用い，温度の作用効果と此 ベられる体感温度として表示することを試みた。

\section{材料および方法}

供試豚は，ケージ飼育のランドレース種去勢誐 8 頭を 用いた，实験は，18〜22 週鈋時に行ない，体重は60〜 $75 \mathrm{~kg}$ であった，㬰験は，環境調節室で行ない，疅境温 
池内・山本・山本

度は，乾球温度 (DBT) $14,18 ， 22 ， 26 ， 28 ， 30 ， 32$ お 上び $34^{\circ} \mathrm{C}\left( \pm 1.0^{\circ} \mathrm{C}\right)$ の 8 段階に設定したが，湿度は， 無調節であった.な拈，生理反応測定開始約 1 時間前に， $25^{\circ} \mathrm{C}$ 飼育温度から各実験温度に設定し, 30 分前に飼料 を取り除いた。送風は，1頭ごとに $11 \mathrm{~cm}$ 口径の送風機 (Centaur, Japan Servo Model CT 3 B 55A) 2 台を然 験用ヶージ（日本養豚ヶージ製作所，NY 式試験用ヶー ジ)上部に設置して行ない，風速( AV) は，豚を除い たケージ内で，無送風 $(0.05) ， 0.4:(0.3 \sim 0.5) ， 0.7$ ， $(0.5 \sim 0.9), 1:(0.7 \sim 1.4), 2 \mathrm{~m} / \mathrm{s}(1.5 \sim 2.5 \mathrm{~m} / \mathrm{s}) \mathrm{K}$ なるように 5 区を設定した，風の感作は，同一実験温度 下に招いて，無送風から $2 \mathrm{~m} / \mathrm{s} へ$ ，順に 30 分間ずつ負 荷した.

生理反応の測定は, 呼吸数, 心拍数, 直腸温扔よび皮 䖉温について行ない，友煵温の測定部位は，耳端，耳根 背乩上び後肢管部の左右 8 部位とした. 皮阑温之直腸温 の測定には，銅・コンスタンタン熱電対（岡崎製作所, $\mathrm{EXD} タ イ フ ゚ \mathrm{CC}, 0.32 \times 2 \mathrm{C}$ ) を用い, 皮膚温は, あら かじめリード線を接着剤で皮毛に固定した後, 前毛した 測定部位に感熱部をテーブ(ニチバン, $25 \mathrm{~mm}$ ホワイト テープ）で密着させ，また，直腸温は，肛門から約 $10 \mathrm{~cm}$ の部位汇感熱部をそう入し，いずれもデジタルレコー ダー（タケダ理研，TR-2721）を用い, 1 分ごとに記録 した。呼吸数は、腹囲型呼吸ピックアップを用い、ま た，心拍数恃針電極を用いて，雨者老多用途監視記録装 置（日本光電工業 $\mathrm{KK}$ ) で連続記録した. それぞれの生 理反応の平均值は, 原則として風速感作後 20〜30 分閒の 横臥安新㭙の颠から求めた。

\section{結果}

DBT と备生理反応（8頭の平均偭と標準偏差）の関 保を図1に示した，DBT に対する皮成温の変化の大き さは，订端〉耳根〉背の順であり，末端部汪と大きか, た. 出た, 各皮原温の变化とその個体間のふれ幅は, $22^{\circ} \mathrm{C}$

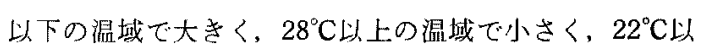
上の温域では，部位間の差は，ほとえどみられなかった。 測定は，豚の休息・横卧状態で行なわれたが，後肢管部 は，測定中腹の下になったり，ケージ外に出るなどして， 他の部位上は異なり AVによる著しい低下反応は認めら れなかった，呼吸数は， $22^{\circ} \mathrm{C}$ 以上で $\mathrm{DBT}$ 上昇に伴い増 加した，直晹温は， $28^{\circ} \mathrm{C}$ 以上の高温区で上暑し， $18^{\circ} \mathrm{C}$ と $22^{\circ} \mathrm{C}$ で最も低かった。 心拍数は, $14 \sim 28^{\circ} \mathrm{C} て ゙ \mathrm{DBT}$ 上昇 に伴いわずかながら增加し，28ㄷで最高值を示した。

图 2 に各生理反応に及ぼす DBT と、 $\mathrm{AV}$ の関係を 示した，耳端（図 2-[A]）では，AVの增加に対する皮清

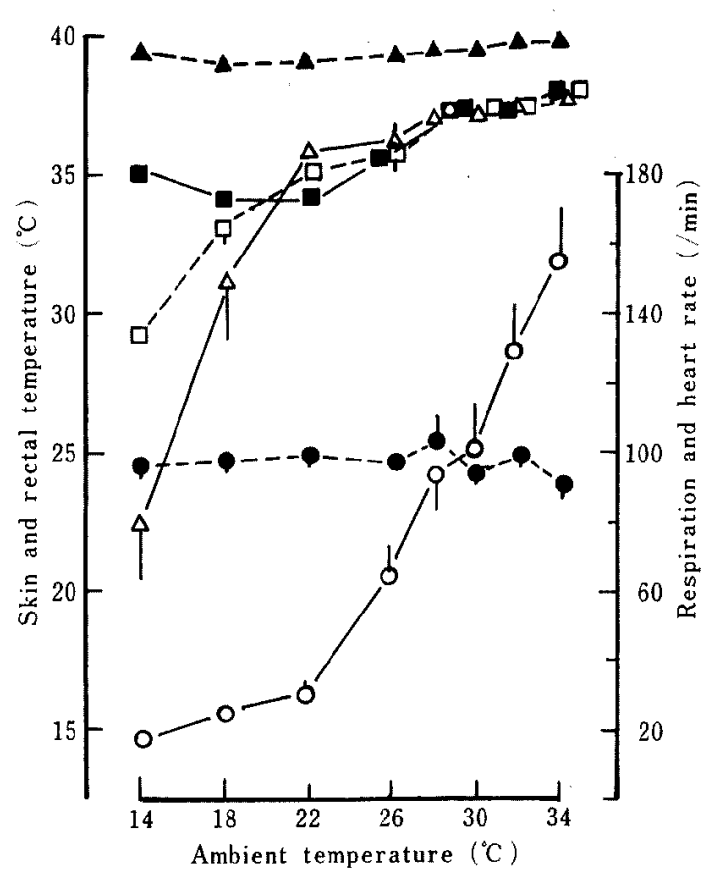

Fig. 1. Relationships between ambient temperature and physiological responses under still air conditions $(0.05 \mathrm{~m} / \mathrm{s})$ in pigs. Values are mean $\pm \mathrm{SD}$ of eight pigs. $\Delta=$ rectal temperature, $\boldsymbol{m}=$ skin temperature of shank, $\square=$ skin temperature of back of thorax, $\Delta=$ skin temperature of tip of ear, - heart rate and $O=$ respiration rate.

温の明らかな低下は，DBT 14〜26 ${ }^{\circ} \mathrm{C}$ 温域で認められ， $30^{\circ} \mathrm{C} て ゙ は ， わ す ゙ か と な り ， 32^{\circ} \mathrm{C}$ と $34^{\circ} \mathrm{C}$ 高温域では, $\mathrm{AV}$ 增加による影響は認められなかった。なお，皮膚温が $36^{\circ} \mathrm{C}$ 前後に達する $\mathrm{DBT}$ は，各部位とも無送風時には $22^{\circ} \mathrm{C}$ であったが, $1 \mathrm{~m} / \mathrm{s}$ 区では，26〜 $28^{\circ} \mathrm{C}$ となり，4〜 $6{ }^{\circ} \mathrm{C}$ 高くなっていた，AV の增加尤る呼吸数（図 2[B])の明らかな淢少は, DBT $22 \sim 30^{\circ} \mathrm{C}$ の温域で認めら れ, $14^{\circ} \mathrm{C} と 18^{\circ} \mathrm{C}$ 低温域と $32^{\circ} \mathrm{C}$ と $34^{\circ} \mathrm{C}$ の高温域で， その明らかな影響は認められなかった。直腸温（㓙2〔C]）は, 18〜22 $\mathrm{C} て ゙$ 最低值を示し， $18 \sim 26^{\circ} \mathrm{C}$ の温域で は, 風速の影響は認められなかった， $28 \sim 36^{\circ} \mathrm{C}$ 高温域 においてては，送風により，上昇した直腸温の明らかな降 下も，また高温による明らかな上昇反応も認められなか

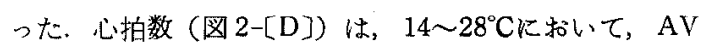

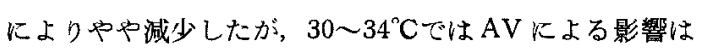
明らかでなかった。

考察

各生理反応と DBT および AVとの関俰から，両者の 

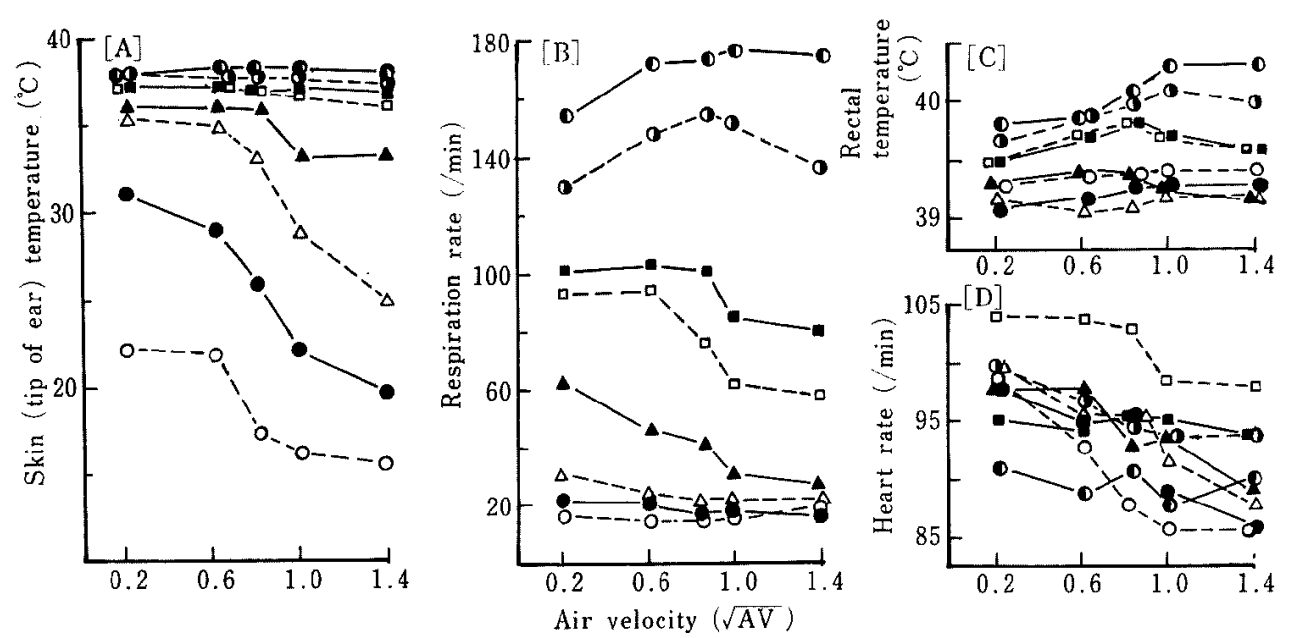

Fig. 2. Relationships between air velocity and physiological responses in pigs at eight ambient temperatures. Values are means of eight pigs. $\quad=14^{\circ} \mathrm{C}, \quad=18^{\circ} \mathrm{C}, \Delta=22^{\circ} \mathrm{C}, \Delta=26^{\circ} \mathrm{C}, \square=28^{\circ} \mathrm{C}, \boldsymbol{\square}=30^{\circ} \mathrm{C}$, $\boldsymbol{O}=32^{\circ} \mathrm{C}, \boldsymbol{D}=34^{\circ} \mathrm{C}$.

变化に対し䫒著な反応を示した皮虞温と呼㖟数を指標と し, DBT と $\sqrt{\mathrm{AV}}$ の作用関係を検討した.なお，皮简 温のらら，後肢管部を検討部位からはずした。

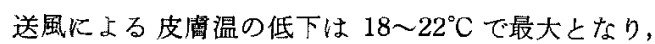

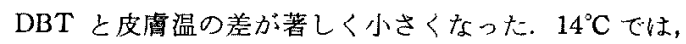

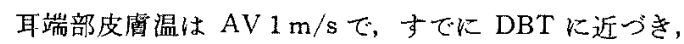
さらに， $\mathrm{AV}$ が增加しても変化はわずかであっだ. $26^{\circ} \mathrm{C}$ 以上の温域では，DBT の上昇に伴5皮雐温の上昇率は

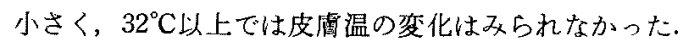

体表温度は，表在血管を流れる血流量に伴って変化し， 血流の变化は、視床下部温やDBT に支配されている ${ }^{11)}$.

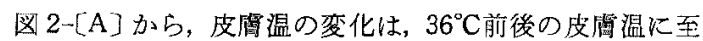
るまでの温域で大きく，表在血管の収縮・払張運動が活 発に行なわれていたことを示した。

皮庴温が $36^{\circ} \mathrm{C}$ 以上となる温域では DBT 上昇に伴らて の変化はきわめて小さく，末端部之体幹部皮處温の差む なくなることから， $36^{\circ} \mathrm{C}$ 前後の皮涌温は，表在血管が抎 張しきったことを示するのと考えられた．皮膚温が $36^{\circ} \mathrm{C}$ 前後に達する DBT を表在血管扗張臨界温度とすると， 本実験の場合，無送風区で $22^{\circ} \mathrm{C}, 1 \mathrm{~m} / \mathrm{s} て ゙ 26 \sim 28^{\circ} \mathrm{C}$ であ り， I m/s の AVにより臨界温度が $4 \sim 6^{\circ} \mathrm{C}$ 高くなり,

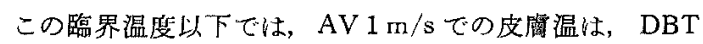
で 4 $6^{\circ} \mathrm{C}$ 低い無送風の皮有温に汪涪等しかった。

図 3 は，皮唐温 (耳端部) と呼吸数拉よび直腸温の関 係を示したるので，呼吸数や直腸温の上昇が，表在血管 払張臨界温度以上の温域で，はじ好認められることを 示している。豚の適温域とされる $18 \sim 22^{\circ} \mathrm{C}$ に当る温域
の直腸温は最も低く，末た，皮留温は，耳端部で 23 $35^{\circ} \mathrm{C}$, 背部で $27 \sim 35^{\circ} \mathrm{C}$ であった， $22^{\circ} \mathrm{C}$ 以下では直晹温 は，皮㾝温が低下寸ると，むしろ上昇する傾向去し，
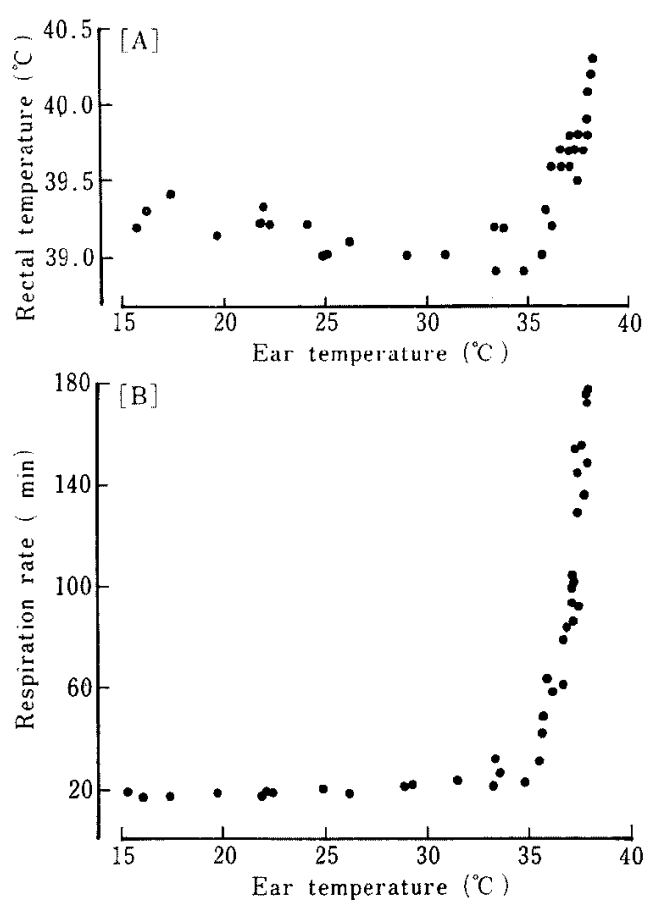

Fig. 3. Relationships between skin temperature of tip of ear and [A] rectal temperature and [B] respiration rate in pigs. Values are means of eight pigs. 
池内・山本・山本

低温や送風により，やや過剩な産熱反応が引き起こされ た結果之思われた。

耳端，耳根拉よび背部の各皮虐温に及ぼす DBT と $\sqrt{\mathrm{AV}}$ の作用劏合を重回㷌分析によって求め，次の結果 を得た。

功端部 $\cdot \mathrm{Y}_{1}=11.20+0.96 \mathrm{X}_{1}-3.67 \mathrm{X}_{2}, \mathrm{R}=0.92^{* *}$ 耳根部 $\cdot Y_{2}=17.13+0.76 \mathrm{X}_{1}-3.19 \mathrm{X}_{2}, \quad R=0.91^{* * *}$ 背 部 $\cdot \mathrm{Y}_{3}=20.07+0.63 \mathrm{X}_{1}-2.79 \mathrm{X}_{2}, \mathrm{R}=0.94^{* *}$

$\left(\mathrm{Y}\right.$ : 皮店温, $\left.\mathrm{X}_{1}: \mathrm{DBT}, \mathrm{X}_{2}: \sqrt{\mathrm{AV}},{ }^{* *} \mathrm{P}<0.01\right)$

$\mathrm{DBT} と \sqrt{\mathrm{AV}}$ の作用割合は, 耳端, $1: 3.8$, 耳根, 1:4.2, 背, 1:4.4となり,ほぼ 1:4の関係にあり, DBT と $\sqrt{\mathrm{AV}}$ の関係を一元化した体感温度 $(\mathrm{ET}(\mathrm{DBT}, \mathrm{AV}))$ は，次のよらに提示できると教られた。

\section{$\mathrm{ET}(\mathrm{DBT}, \mathrm{AV})=\mathrm{DBT}-4 \cdot \sqrt{\mathrm{AV}}$}

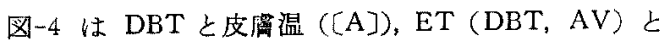
皮膚温 (〔B]) との関係を示したもので後者は比較的無 理のない反応曲線を描いた。

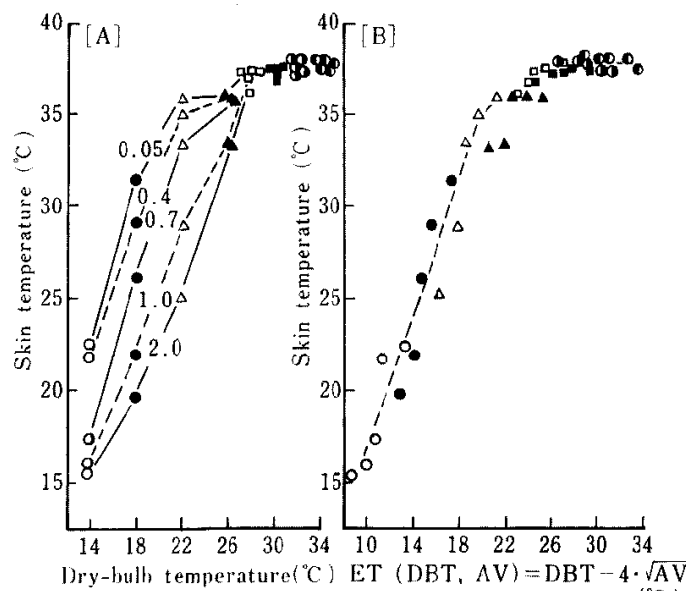

$\left({ }^{\circ} \mathrm{C}\right)$

Fig. 4. Relationships between skin temperature of tip of ear and [A] dry-bulb temperature and $[B]$ effective temperature in pigs. Numbers are air velocity $(\mathrm{m} / \mathrm{s})$ in $[\mathrm{A}]$.

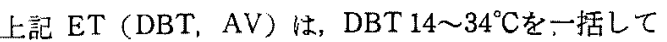
行なった結果であるが，皮膚温の変化は温域によって著 しく翼なることから，变化の大きかったa） $14 \sim 28^{\circ} \mathrm{C} の$ 温域と比較的变化の小さかった b) $26 \sim 34^{\circ} \mathrm{C}$ に区分し て，两者の作用割合の再娭討を陚みた。

a) DBT: $14 \sim 28^{\circ} \mathrm{C}$

$\mathrm{Y}_{1}($ 耳端 $)=6.33+1.30 \mathrm{X}_{1}-5.98 \mathrm{X}_{2}, \mathrm{R}=0.96^{* *}$ $\mathrm{Y}_{2}$ (耳根) $=13.22+1.04 \mathrm{X}_{1}-5.09 \mathrm{X}_{2}, \mathrm{R}=0.94^{* *}$ $\mathrm{Y}_{3}($ 背 $)=18.56+0.77 \mathrm{X}_{1}-4.40 \mathrm{X}_{2}, \quad \mathrm{R}=0.97^{* *}$ b) DBT: $26 \sim 34^{\circ} \mathrm{C}$

$$
\begin{array}{ll}
\mathrm{Y}_{1}=27.67+0.33 \mathrm{X}_{1}-0.58 \mathrm{X}_{2} & \mathrm{R}=0.82^{* *} \\
\mathrm{Y}_{2}=30.06+0.26 \mathrm{X}_{1}-0.51 \mathrm{X}_{2} & \mathrm{R}=0.82^{* *} \\
\mathrm{Y}_{3}=25.64+0.39 \mathrm{X}_{1}-0.70 \mathrm{X}_{2} & \mathrm{R}=0.88^{* *}
\end{array}
$$

( $\mathrm{Y}$ : 皮盾温, $\mathrm{X}_{1}$ : DBT, $\left.\mathrm{X}_{2}: \sqrt{\mathrm{AV}},{ }^{* *} \mathrm{P}<0.01\right)$

DBT と $\sqrt{\mathrm{AV}}$ の作用制合住, 耳端, 耳根, 背で 14 $28^{\circ} \mathrm{C}$ でそそれそれ $1: 4.6 ， 1: 4.9,1: 5.7 ， 26 \sim 34^{\circ} \mathrm{C} て ゙$ は, それぞれ $1: 1.8,1: 2.0,1: 1.8$ となり，14〜34 ${ }^{\circ} \mathrm{C}$ の值に比べ，前者では $\sqrt{\mathrm{AV}}$ の作用割合が大きく，後者 では，小さかった．この結果は, 高温域に比べ常温から 低温域での $\sqrt{\mathrm{AV}}$ の作用割合が大きくなる㑯向を示寸 とともに，皮阅温に上る判断に限界のあることを暗示す るものと考えられた，また，部位による作用の違いは， 表在血管の密度や被毛密度，あるいは皮下組織の違いな と構造や機能の違いに起因すると考兄られたが，他方， 作用した AVが部位によって一定ではなかったことも原 因したと思われた．特に耳翼は，動物自身の動きも多 く，風に対する向きむ変化した，宇和川ら および脚の表面温度を指標に $1 \mathrm{~m} / \mathrm{s}$ は，DBT が約 $3^{\circ} \mathrm{C}$ 低下した条件と等価であったとしており，豚との違い は，比較的わずかであったか，産卵鶏と豚との体表樥造 やその機能の違いなどから，両者間の違いを理解できる と思われた。

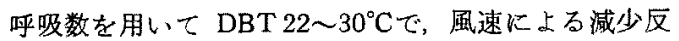
応を皮盧温と同様の処理を行ない以下の結果を得た。

$$
\begin{aligned}
& \mathrm{Y}_{4}=-161+9 \mathrm{X}_{1}-24 \mathrm{X}_{2} \quad \mathrm{R}=0.94^{* *} \\
& \mathrm{Y}_{4}: \text { 呼吸数 (回/分) }
\end{aligned}
$$

DBT と $\sqrt{\mathrm{AV}}$ の作用割合は、はほ $1: 2.7$ となった。 皮简温で求めた作用割合之呼吸数で求めた作用割合に 相違が認められたのは，第1にDBT とAVk対する両 反応の性筫が温域により異なっていだこと，第 2 と指標 として用いた皮阔温の部位は，AV の影響を㨁接受けて いた部位に限定されていたが，呼吸数は，風の当ってい ない部位の影偣も含めた効果を示したことによると考兄 られた。

MORRISON ら ${ }^{12)}$ は，或に及ぼす温度の影偣について適 温から高温域で検討し, 直腸温と体表温への湿度の影響 が，DBT に比べ著しく小さいことを示している．また， INGRAM $^{7}$ や山本 $5^{9)}$ の報告から，育成豚への DBT と湿 球温度 (WBT, ${ }^{\circ} \mathrm{C}$ ) の作用割合は，0.6 0.65: 0.35〜 0.4 とされて特り，DBT に比べ WBT の影響割合が小 さいことがわかる，本実験では，湿度は無調節であった が，測定したWBT を利用 $\mathrm{L} ， \mathrm{DBT}$ とWBT を体感温 度 $(\mathrm{ET}(\mathrm{DBT}, \mathrm{WBT})=0.6 \cdot \mathrm{DBT}+0.4 \cdot \mathrm{WBT})$ として 求め, $\sqrt{\mathrm{AV}}$ との作用関係を検討した結果 $14 \sim 28^{\circ} \mathrm{C} に$ 


\section{豚に対する風速作用の体感温度}

おいて，ET(DBT，WBT) と $\sqrt{\mathrm{AV}}$ の作用割合は， DBT のみで検討した場合とかわらず，26〜 $34^{\circ} \mathrm{C}$ におい ては各部位とも風の作用割合がやや大きくなった。束

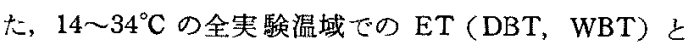
$\sqrt{\mathrm{AV}}$ の作用割合は 1:4.4 で DBT との関係に比べ $\sqrt{\mathrm{AV}}$ の作用割合がやや大きかった，皮膚温哇 DBTに対応し た変化を強く正し，湿度の影響が大きくなると思われる 高温域では，すでにその变化は，ほとんど認められず皮 嘚温を指標にした湿度の解析は，不可能と思われた。し たがって，本実験では，先に述べたよらにDBTと $\sqrt{\mathrm{AV}}$ の作用関係でまとめることにした。

MOUnT and INGRAM ${ }^{3)}$ が, DBT 15〜35 ${ }^{\circ} \mathrm{C}$ 㳑域で, 豚 の胸背部に当てた熱流計で測定した䫒熱放散量からは, ET $(\mathrm{DBT}, \mathrm{AV})=\mathrm{DBT}-10 \sim 18 \cdot \sqrt{\mathrm{AV}}$, すなわり, $1 \mathrm{~m} /$ s の作用は， $-10 〜-18^{\circ} \mathrm{C}$ に等洒であると算出され，今 回得た値と著しく異なるむのであったまた，CLOSE ら〉 の熱発生量を指標にした場合も、 $\sqrt{\bar{A} \bar{V}}$ 作用は，かなり 大きなるのと推定されて扣り，判定に用いる指標によっ て，その作用割合が異なることを示した。

しかしなからら、本実験のように生理反応を利用 し, AV 作用を積極的に部洒することは，寒冷時の防風並びに署 熱時の送風の効果をより具体的に示すものであり，風速 の合理的制御に役立つもの上思われた。

謝辞

本研究は，文部省科矿，総合砂究 A（課題番宂 536019 ,
研究代表者森田㭬磨教授)の補助を受けて行なった．生 理反忘の測定に協力いただいた金広大君と坂本 清君 に感謝いたします。

\section{文献}

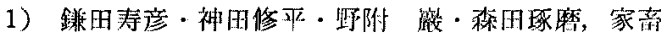
の管理, 17: 71-76. 1982.

2) Jenkinson, D. McE., in comparative physiology of desert animals (Malory, G. M. O., Ed.), pp. 345-356. Butterworths, London. 1972.

3) Mount, L. E. and D. L. Ingram, Res. Vet. Sci., 6: 84-91. 1965.

4) Close, W. H., R. P. Heavens and D. Brown, Anim. Prod., 32: 75-84. 1981.

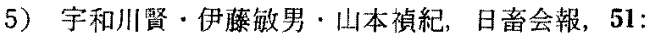
471-477. 1980.

6) Bianca, W., Nature, 195: 251-252. 1962.

7) INGRAM, D. L., Res. Vet. Sci, 6: 9-17. 1965.

8) 三村耕・山本襀紀 - 伊藤敏男 - 住由正彦・新谷 勝弘・藤井筀融，日畜会報，42：493-500，1971.

9）山本禎紀 - 所 和揚 ·富島信行 - 伊藤敏男 -三村 耕，日畜会報，42：609-616，1971。

10）山本禎紽 - 伊藤敏男 - 伊藤久孝・松本下秋 - 三村 耕，日畜会報，46：161-166。 1975.

11) Ingram, D. L. and K.F. Legge, J. Physiol., 215: 693-707. 1971.

12) Morrison, S. R., H. Heitman, Jr. and T.E. Bond, Int. J. Biometeor., 13: 135-139. 1969. 


\title{
The Effect of Ambient Temperature and Air Velocity on Physiological Responses of Fattening Pigs and an Assessment of Air Velocity into Effective Temperature
}

\author{
Shunsaku IKeuchi, Aya Yamamoto \\ and Sadaki Yamamoto
}

Faculty of Applied Biological Science, Hiroshima

University, Fukuyama 720

Eight Landrace barrows, kept in each cage, were exposed to air velocities between $0.05-2$ $\mathrm{m} / \mathrm{s}$ at ambient temperatures from $14-34^{\circ} \mathrm{C}$. Skin temperature at four sites (tip and base of ear, back of thorax and shank of hind leg), rectal temperature, respiration rate and heart rate were recorded. The rate of increase in skin temperature with raised DBT was faster below $22^{\circ} \mathrm{C}$ and slow above $26^{\circ} \mathrm{C}$, also site differences in skin surface temperature disappeared above $26^{\circ} \mathrm{C}$. The rate of decrease in skin temperature with increasing air velocity was higher below $26^{\circ} \mathrm{C}$ and the effect of air velocity approximately disappeared above $30^{\circ} \mathrm{C}$. When ambient temperature were between $18-22^{\circ} \mathrm{C}$, rectal temperature was the lowest. Both the rate of decreasing of raised rectal temperature due to air velocity and the rate of rise of rectal temperature due to raised DBT were not clearly responsed by increasing air velocity above $28^{\circ} \mathrm{C}$. The increase in respiration rate due to raised DBT was clearly repressed by increasing air velocity only between $22-30^{\circ} \mathrm{C}$. Heart rate was less affected by both ambient temperature and air velocity. The effective ratio of DBT: $\sqrt{\mathrm{AV}}$ on the skin temperatures is $1: 4$ approximately. The contribution of air velocity to effective temperature can be expressed as follows, ET (DBT, AV) $=\mathrm{DBT}-4 \cdot \sqrt{\mathrm{AV}}$. This coefficient of $\sqrt{\mathrm{AV}}$ tended to decrease above $26^{\circ} \mathrm{C}$ and to increase below $26^{\circ} \mathrm{C}$.

Jpn. J. Zootech. Sci., 55 (11): 815-820, 1984 